\title{
ISS Utilization and Countermeasure Validation: Implementing the Critical Path Roadmap to Reduce Uncertainties of Extended Human Spaceflight Expeditions
}

\author{
Lauren B. Leveton ${ }^{1}$, Judith L. Robinson ${ }^{2 a}$, and John B. Charles ${ }^{2 b}$. \\ ${ }^{1}$ Universities Space \& Research Association, Space Life Sciences Program 3600 Bay Area Blvd, Houston TX 77058 , \\ 703/916-0643,lleveton@bellatlantic.net \\ ${ }^{2 a}$ Program Integration Office, Space and Life Sciences Directorate, Johnson Space Center, Houston, TX 77058 , \\ 281/483-1165, judith.l.robinson1@jsc.nasa.gov \\ ${ }^{2 b}$ Mission Science Office, Space and Life Sciences Directorate, Johnson Space Center, Houston, TX 77058 , \\ 281/483-7224, john.b.charles1@jsc.nasa.gov
}

\begin{abstract}
Human exploration of space requires the ability to understand and mitigate risks to crews exposed to the conditions associated with such missions. This becomes a greater imperative as we prepare for interplanetary expeditions involving humans who will be subjected to long transit periods in microgravity as they travel to a distant planet such as Mars, embark and live on the planet's surface for an extended time, and finally, return to the $1 \mathrm{~g}$ environment of Earth. We need to know, more definitively, what the human health, safety, and performance risks are, and how to prevent or counteract them throughout all phases of a long duration mission. The Johnson Space Center's Space and Life Sciences Directorate along with the National Space Biomedical Research Institute (NSBRI) have been engaged in a strategic planning effort that identifies the most critical risks confronting humans who will venture forth on such missions and the types of research and technology efforts required to mitigate and otherwise reduce the probability and/or severity of those risks. This paper describes the unique approach used to define, assess and prioritize the risks and presents the results of the assessment with an emphasis on the research and technology priorities that will help us to meet the challenge of long duration human spaceflight missions.
\end{abstract}

\section{RISKY BUSINESS}

The exploration of space with a human presence, particularly expeditions to other planetary surfaces, is an inherently risky business. Radiation exposure, inadequate atmosphere and water, extreme temperatures, prolonged isolation and confinement within an enclosed environment, and physiological alterations due to microgravity conditions are all potential hazards that can jeopardize any mission at any time. Ensuring the safety, health and well being of the crews that embark on such missions requires the ability to both understand and mitigate risk. In fact, in some instances, such as radiation exposure, the Agency has a legal responsibility to inform crews of potential risks to their health and safety. This makes identification and quantification of the risk, determination of minimally acceptable levels of risk, and development of risk reduction solutions, equally important steps.

\section{Approach}

Approximately three years ago, the Agency's lead center for the human elements of spaceflight (the Johnson Space Center), along with the National Biomedical Research Institute (NSBRI) (which has the lead role in developing countermeasures) initiated an activity to identify the most critical risks confronting extended human spaceflight. Two salient factors influenced this activity: first, what is needed to enable a go/no go decision for embarking on extended human spaceflight missions; and second, what is needed to address known and potential health, safety and performance risks associated with such missions. A unique approach was used to first define and assess those risks, and then to prioritize them. This activity was called the Critical Path Roadmap and it represents an opportunity to develop and implement a focused and evolving program of research and technology designed from a "risk reduction" perspective to prevent or minimize the risks to humans exposed to the space environment. 


\section{Key Elements of the Critical Path Roadmap}

The elements comprising the Critical Path Roadmap are shown in Figure 1. 'Risk is defined as exposure to the space environment resulting in dysfunctional physiological or behavioral adaptation, injury, illness, or loss of life or mission objectives. Risk factors represent conditions associated with an increased probability of the occurrence of the risk and can operate singly or in combination to contribute to the risk's occurrence. Critical questions encompass the key research and technology issues that must be addressed to understand the risk and its resolution.

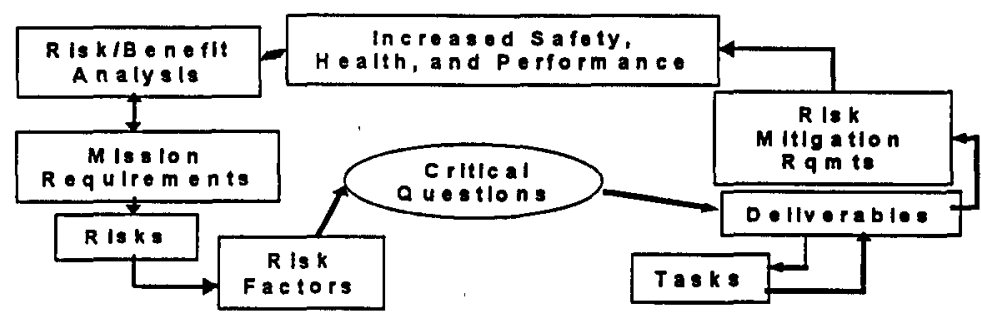

FIG URE 1. Critical Path Roadmap Elements.

Critical questions lead to specific deliverables and corresponding tasks. Deliverables are specific end-items that can be identified, completed, and made available at known dates. Tasks are the specific research and technology projects addressing the questions, providing deliverables, and ultimately the risk mitigation requirements.

Once risks have been identified, characterized and compared, an important step is the evaluation of a range of alternative options and selection of outcomes. This is referred to as risk or, costbenefit analysis (Hohenemser and Kasperson, 1982; Swaney, 1997). Decisions concerning resource allocation are based on valuations of what critical risks require mitigation, what knowledge is needed to better understand and mitigate the risk to what level of acceptability, the development status of the mitigation, an assessment of current tasks associated with the risk and critical questions, mission parameters and resources (e.g., available crew time, power and space).

\section{The Critical Path Roadmap Process}

Informed decisions about risk reduction options are the product of a combination of two interacting processes analysis and deliberation. While there are no set rules or standard operating procedures on how to achieve the right' balance, both are necessary (NRC, 1996). The Critical Path Roadmap utilized an iterative approach that combined review, analysis and deliberations at three stages analogous to expanding concentric circles. Each built upon the results of the preceding stage and was characterized by a more objective valuation.

\section{Stage 1: Risk Identification and Characterization}

The context for risk identification was a possible future agency decision to embark on long duration human exploration class missions. A group of approximately 25 intramural scientists, engineers, and program managers from JSC, familiar with operational aspects of human spaceflight, met weekly for six months to identify the initial set of risks. A review of reports from previous advisory committees (e.g., NASA Countermeasure Task Force Final Report, 1997; NRC 1997, 1995, 1987; NAC, 1992) was undertaken to help identify risks and critical issues. Risks were determined for missions of varying duration (i.e., Shuttle up to 16 days; ISS up to 180 days; Lunar up to 180 or more days; and Mars 500+ days). However, a decision was made to focus on "worst case scenario," (Table 1).

TABLE 1. Mars Design Reference Mission.

Earth Departure 2014 with Crew of Six

Transit Out - 161 Days; Retum - 154 Days

Mars Surface Stay 569 Days

$4 \mathrm{G}$ Transitions $\quad 1 \mathrm{G}$ to $0 \mathrm{G} ; 0 \mathrm{G}$ to $1 / 3 \mathrm{G} ; 1 / 3 \mathrm{G}$ to $0 \mathrm{G} ; 0 \mathrm{G}$ to $1 \mathrm{G}$

High G Loading , 3-5 (TBD) G During Aerobraking and Landing 
The resulting list of risks became part of the ensuing discussions during the next several months that further combined and refined the list of risks, with the focus on exploration class missions. In addition, a set of criteria to characterize the risks was developed and applied. The risk scoring criteria included the following measures:

- Expected Occurrence of Risk with No Risk Mitigation or Countermeasures Present

- Expected Occurrence of Risk with Current Countermeasures

- Severity of Impact on Mission Objectives

- Severity of Impact on Crew Health

- Risk Mitigation Status

The review and deliberations, at this stage, produced approximately 100 risks across the following 11 disciplines:

- Advanced Life Support

- Bone Loss

- Cardiovascular Alterations

- Clinical Capabilities

- Environmental Health

- Food and Nutrition
- Human Behavior and Performance

- Immunology, Infection and Hematology

- Muscle Alterations and Atrophy

- Neurovestibular Adaptation

- Radiation Effects

\section{Stage 2: Further Risk Identification, Characterization and Ranking}

The second stage of the process involved the participation of a diversified group of extramural scientists representing the expertise from the newly formed National Space Biomedical Research Institute (NSBRI). In January 1998, approximately 20 members of the NSBRI met with the group of JSC intramural scientists in a threeday workshop to establish discipline risk area teams and to review, define and assess a final set of risks in each discipline. Risk assessment included applying the risk scoring criteria and rank-ordering the risks within the 11 disciplines. The same group developed a core set of critical questions that must be addressed to mitigate the risks.

In June 1998, the Critical Path Roadmap was presented to all discipline team members (approximately 200 scientists) of the NSBRI and further refinement of the risks and critical questions continued over the next several months. The risks and critical questions were then presented to approximately 300 NASA life scientists at the First Biennial Space Biomedical Investigators Workshop held January, 1999 (NASA, 1999). The last step was validation of the refined set of risks and critical questions. This was accomplished through a comparison by discipline risk area teams of the issues and recommendations contained in a recent report of the Committee on Space Biology and Medicine (NRC, 1998) with the Critical Path Roadmap discipline area risks and critical questions.

\section{Stage 3: Cross-Risk Prioritization}

Cross-risk prioritization was accomplished with the participation of a small panel of experts comprised of individuals who represented management of biomedical research, astronaut health and safety, medical operations, and science policy/planning. There was considerable discussion, over several months, on how to prioritize the risks and develop a consensus for a categorization that compared the relative importance of risks based on the discipline experts' assessment using the risk scoring criteria and the rank-ordering of the risks. Table 2 shows the categorization. (Initial comparison was made across the set of biomedical risks, the remaining "engineering systemtype" risks, such as unsafe food systems and acceptable atmosphere, were subsequently categorized.)

TABLE 2. Assignment of Risk Types/Priorities.

\begin{tabular}{|c|c|c|c|c|}
\hline & $\begin{array}{c}\text { Demonstrated Serious } \\
\text { Problem }\end{array}$ & $\begin{array}{l}\text { Suspected Serious } \\
\text { Problem }\end{array}$ & $\begin{array}{l}\text { Demonstrated } \\
\text { Problem }\end{array}$ & $\begin{array}{l}\text { Suspected } \\
\text { Problem }\end{array}$ \\
\hline $\begin{array}{l}\text { No Countermeasure } \\
\text { (CM) Concept }\end{array}$ & $I$ & II & II or III & III \\
\hline $\begin{array}{l}\text { CM Concept } \\
\text { - No Ground Validation }\end{array}$ & II & II & II or III & III \\
\hline $\begin{array}{l}\text { CM Concept } \\
\text { - No Space Verification }\end{array}$ & III & III & III & III \\
\hline $\begin{array}{l}\text { Effective Operational } \\
\mathrm{CM}\end{array}$ & IV & Not applicable & IV & Not applicable \\
\hline
\end{tabular}




\section{Results}

The process of careful review, analysis and deliberations resulted in a credible, rank-ordered, and prioritized set of critical risks that require risk mitigation strategies designed to prevent or reduce risks to within acceptable levels for human exploration class missions. This section presents some of the specific results to date. It is important to emphasize that while the structure of the Critical Path Roadmap is a static feature, its content is not, and will continue to evolve and change as knowledge is obtained both about the risks and their mitigation.

\section{Risk Ranking and Cross-Risk Prioritization}

The risk identification and characterization resulted in a total of 55 critical risks across the 11 disciplines, 225 critical questions, and 100 different risk factors. The results of the risk identification, ranking and cross risk prioritization are shown in Table 3. (Risk ID refers to the assigned risk identification number.) Approximately 29 percent of the risks were ranked as a " 1, " 22 percent were ranked equally as a " 2 " or " 3 ", and 24 percent of the risks were ranked as " 4 " or more within their respective discipline.

Table 3 shows the results also for the cross-risk prioritization (Type). Approximately 7 percent ( 4 risks) were Type I risks; 49 percent ( 27 risks) were Type II risks, and 43 percent ( 24 risks) were Type III risks. As seen in the table, there are no Type IV risks currently.

TABLE 3. Critical Path Roadmap Risks, Rank, and Risk Type/Priority.

\begin{tabular}{|c|l|c|c|}
\hline ID & \multicolumn{1}{|c|}{ Risk Title } & Rank & Type \\
\hline 1 & Inability to Maintain Acceptable Atmosphere in Habitable Areas & I & II \\
\hline 2 & Inability to Provide and Recover Potable Water & 2 & II \\
\hline 3 & Inadequate Supplies & 2 & II \\
\hline 4 & Inability to Maintain Thermal Balance in Habitable Areas & 3 & II \\
\hline 5 & Inability to Adequately Process Solid Wastes & 3 & II \\
\hline 6 & Inadequate Stowage and Disposal Facilities for Solid and Liquid Trash Generated During Mission & 4 & II \\
\hline 7 & Inadequate Nutrition (Malnutrition) & 1 & II \\
\hline 8 & Unsafe Food Systems & 2 & II \\
\hline 9 & Acceleration of Age-Related Osteoporosis & 1 & I \\
\hline 10 & Fractures (Traumatic, Stress, Avulsion \& Impaired Fracture Healing) & 2 & III \\
\hline 11 & Injury to Soft Connective Tissue or Joint Cartilage, \& Disc Rupture w/ or w/o Neurological & 3 & III \\
\hline 12 & Romplications & & \\
\hline 13 & Occurrence of Serious Cardiac Dysrhythmias & 4 & III \\
\hline 14 & Impaired Response to Orthostatic Stress & 1 & II \\
\hline 15 & Diminished Cardiac Function & 1 & II \\
\hline 16 & Manifestation of Previously Asymptomatic Cardiovascular Disease & 2 & III \\
\hline 17 & Impaired Response to Exercise Stress & 3 & III \\
\hline 18 & Human Performance Failure Because of Poor Psychosocial Adaptation & 4 & III \\
\hline 19 & Human Performance Failure Because Sleep and Circadian Rhythm Problems & 1 & I \\
\hline 20 & Human Performance Failure Because of Human System Interface Problems \& Ineffective Habitat, \\
& Equipment, Design, Etc. & 3 & II \\
\hline 21 & Human Performance Failure Because of Neurobehavioral Dysfunction & III \\
\hline 22 & Infections & 4 & III \\
\hline 23 & Carcinogenesis Caused by Immune System Changes & 1 & III \\
\hline 24 & Altered Hemodynamics \& Cardiovascular Dynamics from Altered Blood Components & 1 & III \\
\hline 25 & Altered Wound Healing & 1 & III \\
\hline 26 & Altered Host-Microbial Interactions & 2 & III \\
\hline 27 & Allergies and Hypersensitivity Reactions & 3 & III \\
\hline
\end{tabular}


TABLE 3. Critical Path Roadmap Risks, Rank, and Risk Type/Priority (Continued).

\begin{tabular}{|c|c|c|c|}
\hline ID & Risk Title & Rank & Type \\
\hline 28 & Loss of Skeletal Muscle Mass, Strength, and/or Endurance & 1 & II \\
\hline 29 & $\begin{array}{l}\text { Inability to Adequately Perform Tasks Due to Motor Performance, Muscle Endurance, and } \\
\text { Disruption in Structural and Functional Properties of Soft \& Hard Connective Tissue }\end{array}$ & $\overline{1}$ & II \\
\hline 30 & $\begin{array}{l}\text { Inability to Sustain Muscle Performance Levels to Meet Demands of Performing Activities of } \\
\text { Varying Intensities }\end{array}$ & 2 & $\overline{\text { II }}$ \\
\hline 31 & $\begin{array}{l}\text { Propensity to Develop Muscle Injury, Connective Tissue Dysfunction, and Bone Fractures Due to } \\
\text { Deficiencies in Motor Skill, Muscle Strength and Muscular Fatigue }\end{array}$ & 3 & III \\
\hline 32 & Impact of Deficits in Skeletal Muscle Structure and Function on Other Systems & $\overline{\mathrm{NR}}$ & III \\
\hline 33 & $\begin{array}{l}\text { Disorientation and Inability to Perform Landing, Egress, or Other Physical Tasks, Especially } \\
\text { During/After G-Level Changes }\end{array}$ & 1 & II \\
\hline$\overline{34}$ & Impaired Neuromuscular Coordination and/or Strength & 2 & $\overline{\text { II }}$ \\
\hline 35 & $\begin{array}{l}\text { Impaired Cognitive and/or Physical Performance Due to Motion Sickness Symptoms or Treatments, } \\
\text { Especially During/After G-Level Changes }\end{array}$ & 3 & III \\
\hline 36 & Vestibular Contribution to Cardioregulatory Dysfunction & 4 & III \\
\hline 37 & Possible Chronic Impairment of Orientation or Balance Function Due to Microgravity or Radiation & 5 & III \\
\hline 38 & Carcinogenesis Caused by Radiation & 1 & $\bar{I}$ \\
\hline 39 & Damage to Central Nervous System from Radiation Exposure & 2 & II \\
\hline 40 & $\begin{array}{l}\text { Synergistic Effects from Exposure to Radiation, Microgravity and other Spacecraft Environmental } \\
\text { Factors }\end{array}$ & 3 & II \\
\hline 41 & Early or Acute Effects from Radiation Exposure & 4 & $\overline{\text { II }}$ \\
\hline$\overline{42}$ & Radiation Effects on Fertility, Sterility, and Heredity & 5 & III \\
\hline 43 & Trauma and Acute Medical Problems & 1 & $\bar{I}$ \\
\hline 44 & Toxic Exposure & $\overline{2}$ & II \\
\hline 45 & Altered Pharmacodynamics and Adverse Drug Reactions & 3 & II \\
\hline 46 & Illness and Ambulatory Health Problems & 4 & III \\
\hline 47 & $\begin{array}{l}\text { Development and Treatment of Decompression Illness Complicated by Microgravity-Induced } \\
\text { Deconditioning }\end{array}$ & 5 & III \\
\hline 48 & Difficulty of Rehabilitation Following Landing & 6 & III \\
\hline 49 & $\begin{array}{l}\text { Post-landing Alterations in Various Systems Resulting in Severe Performance Decrements and } \\
\text { Injuries }\end{array}$ & NR & III \\
\hline 50 & $\begin{array}{l}\text { Allergies and Hypersensitivity Reactions from Exposure to the Enclosed Spacecraft \& Other } \\
\text { Environmental Factors }\end{array}$ & 3 & II \\
\hline 51 & $\begin{array}{l}\text { Inability to Maintain Acceptable Atmosphere in Habitable Areas Due to Environmental Health } \\
\text { Contaminants }\end{array}$ & 1 & $\overline{I I}$ \\
\hline 52 & Inability to Provide and Recover Potable Water Due to Environmental Health Contaminants & 2 & II \\
\hline 53 & Inadequate Nutrition Due to Inability to Provide and Maintain a Bioregenerative System & $\overline{1}$ & II \\
\hline 54 & Difficulty of Rehabilitation Following Landing Due to Nutritional Deficiencies & 3 & III \\
\hline 55 & Human Performance Failure Due to Nutritional Deficiencies & 4 & $\bar{\Pi}$ \\
\hline
\end{tabular}

\section{Decisionmaking via the Critical Path Roadmap}

It is the intent of the Critical Path Roadmap to provide the foundation for what is needed to ensure that human spaceflight, now and in the future, is as safe, productive and healthy as possible (given the constraints imposed on a particular mission) regardless of mission duration or destination. As a tool, the Critical Path Roadmap enables the decisionmaker to select among the demonstrated or potential problems for harm those that are to be mitigated and to what degree. The following set of questions are examples of how the Critical Path Roadmap will be used to help guide decisions about selecting research and technology efforts to mitigate the critical risks. 
- Does the research or technology address a specific Critical Path Roadmap risk?

- What Type of risk is addressed? Is it a Type I risk? Is more than one risk addressed by the research?

- What kind of research or tcchnology is represented by the effort (i.e., mechanisms/processes, risk assessment, risk mitigation, or medical diagnosis and treatment)?

- Does the research or technology address a specific critical question? Is more than one question addressed? Is it high priority critical question(s)?

- Does the effort address or provide information about deliverables associated with the critical questions?

- What level of readiness is the research or technology project? Is it a level that is currently required for the risk, critical question, and/or deliverable?

- Are there existing tasks/projects that currently address this risk, critical question, or deliverable?

- Is the timeframe for providing the deliverable(s) compatible with the timeline for the risk?

The extent to which the proposed research or technology effort addresses these questions strengthens the need and priority for the specific task. The evaluation process is evolving to incorporate changes in the knowledge of the risk as well as the status of its mitigation or countermeasure. Known risks without countermeasures (Type I Risks) have priority over potential risks regardless of countermeasure status. The next level of priority distinguishes between Type II and Type III Risks, and so forth. Throughout the process, there is constant weighing of alternative options depending upon the set of benefits and costs associated with the risks and their mitigation.

The problem of what level to reduce risks to is more difficult. It is often the case that knowledge fully quantifying the risk is incomplete. Estimates of the risk's incidence and prevalence are difficult to acquire because of small sample sizes, measurement variability; sustained access to spaceflight or ground-based resources, costs, and other factors. Qualitative information is often used to evaluate the risk and determine acceptability levels through a deliberative process involving expert opinion and discussion (NRC, 1996). Acceptability levels for Critical Path Roadmap risks will be determined through review and deliberations of both quantitative and qualitative information.

The goal over the next decade is to reduce the 55 critical risks, which currently lack validated countermeasures, to minimally acceptable levels thus rendering them Type IV risks, defined as clinically manageable. The specific objective is to achieve countermeasure identification and validation for one-half of the current risks by the year 2006 , and by 2010 , achieve countermeasure identification and validation for the remaining risks. An adequate level of funding to support the necessary research and technology, for the development of effective risk reduction and validated mitigation, along with continued access to spaceflight and crew time are important assumptions underlying such outcomes.

\section{CONCLUSIONS}

The Critical Path Roadmap provides the foundation and tool to enable the decision as well as the implementation of human exploration class missions. It is an integrated, cross-disciplinary strategy to characterize, assess, understand, mitigate and manage the risks associated with long-term exposure to the space environment within overall resource considerations. Its success is built upon several principles.

Rigorous Analyses \& Deliberations. Understanding risk is an important component of informed decisionmaking whether the subject is public health policy, medical treatment, or human spaceflight. A degree of uncertainty is an inevitable part of the process. The presence of scientific uncertainty, different values, and interpretive judgement can influence the outcome (IOM, 1995; NRC, 1996). Successful decisionmaking that results in risk prevention or reduction requires rigorous analyses and deliberations (NRC, 1996). The Critical Path Roadmap is a product of both. Risk analysis was provided by discipline experts who reviewed the scientific evidence about the risks and debated relative importance among the set of risks within their disciplines. Validation was established from a comprehensive comparison of the risks, critical questions and priorities with the issues and recommendations of a recent advisory report (NRC, 1998). The cross-risk prioritization was derived from a group of experts who reviewed the results of the discipline-based risk analysis and developed decision-rules for comparing, categorizing, and prioritizing the relative importance among the risks.

Communication \& Access. Communication of the Critical Path Roadmap and access to its content is important for its success. Success is defined as eliminating or reducing the critical risks by allocating necessary resources to 
research and technology efforts focused on the identified risks, their questions, and associated risk mitigations and countermeasures. Providing the Critical Path Roadmap content to potential investigators increases the probability of delivering effective risk mitigations. Several sources have been employed to achieve this goal. The first is a dedicated user-friendly web site that contains the Critical Path Roadmap content and will incorporate changes as the knowledge base evolves. Second, a basc-lined document will be available in early 2000 containing the elements of the Critical Path Roadmap. In addition, a configuration control board will continue the deliberative process and provide approval and documentation of subsequent changes as the Critical Path Roadmap evolves.

Management, Decisionmaking \& Credibility. The interrelationship among the risks and their mitigation requires coordinated planning, execution and management of resources. The development of timelines for achieving risk mitigation is an important management and decisionmaking tool. One of the key components of the Critical Path Roadmap is the development of risk-based timelines that will integrate across the critical questions, tasks and deliverables related to a risk, or set of risks. Continued review of the Critical Path Roadmap by both management and advisory committees will provide a realistic sounding board to evaluate alternative options for risk prevention or reduction, to avoid missed opportunities and poor decisionmaking, as well as a means for continued credibility.

\section{ACKNOWLEDGMENTS}

The Critical Path Roadmap is an effort originally envisioned by Dr. John A. Rummel, Deputy Director of the Space and Life Sciences Directorate at the Johnson Space Center. Its development has been the product and hard work of many individuals including, Dr. Ronald J. White, Associate Director of the NSBRI, whose insight and participation enriched the entire process, and the discipline risk area team members, particularly the co-leads from both JSC and NSBRI, on whom its continued success remains. There are many others, far too numerous to single out, who contributed to the development of the Critical Path Roadmap.

\section{REFERENCES}

Hohenemser, C., and Kasperson, J.X., "Overview: Towards Detemining Acceptable Risk," in Risk in the Technological Society, edited by C. Hohenemser and J. X. Kasperson, Boulder, Colorado, Westview Press, Inc., 1982, pp. 191-201.

Institute of Medicine, HIV and the Blood Supply: An Analysis in Crisis Descisionmaking, National Academy Press, Washington, D.C., 1995.

NASA, Proceedings of the First Biennial Space Biomedical Investigators' Workshop, Universities Space Research Association, January 11-13, 1999, League City, Texas

NASA, Strategic Considerations for Support of Humans in Space and MoonMars Exploration Missions: Life Sciences Research and Technology Programs: Volume 1, NASA Advisory Counsel, Aerospace Medicine Advisory Committee, June 1992.

NASA, Task Force on Countermeasures: Final Report, Space and Life Sciences, Washington, D.C., May 1997.

National Research Council, Advanced Technology for Human Support in Space, Aeronautics and Space Engineering Board, National Academy Press, Washington, D.C., 1997.

National Research Council, A Strategy for Research in Space Biology and Medicine in the New Century. Space Studies Board, Committee on Space Biology and Medicine, National Academy Press, Washington, D.C., 1998.

National Research Council, A Strategy for Space Biology and Medical Science: For the 1980s and 1990s, Committee on Space Biology and Medicine, Space Science Board, National Academy Press, Washington, D.C., 1987.

National Research Council, Radiation Hazards in Crews of Interplanetary Missions: Biological Issues and Research Strategies, Task Force on the Biological Effects of Space Radiation, Space Studies Board, Commission on Physical Science, Mathematics and Applications, National $\Lambda$ cademy Press, Washington, D.C., 1995.

National Research Council, Understanding Risk: Informing Decisions in a Democnatic Society, edited by P.C. Stern and H.V. Fineberg, Committee on Risk Characterization, Commission on Behavioral and Social Sciences and Education, National Academy Press, Washington, D.C., 1996.

Swaney, J.A., "The Basic Economics of Risk Analysis," in Fundamentals of Risk Analysis and Risk Management, edited by V. Molak, Lewis Publishers, New York, 1997, pp. 99-121. 